\section{Bitterlingstest zum Nachweis einer Schwangerschaft}

\section{T. Arndt}

Bioscientia Institut für Medizinische Diagnostik $\mathrm{GmbH}$, Ingelheim, Deutschland

Synonym(e) Schwangerschaftstest mit dem Bitterling; Schwangerschaftstest nach Glaser und Haempel; Legeröhrentest

Definition Heute obsoleter Bioassay zum Nachweis einer Schwangerschaft mit lebenden Bitterlingsweibchen (Rhodeus amarus).

Beschreibung Auf Zusatz von $5 \mathrm{~mL}$ Schwangerenharn zu $1 \mathrm{~L}$ Wasser tritt schon nach 24 Stunden eine deutlich sichtbare Verlängerung der Legeröhre von zwei- bis viersommerigen Bitterlingsweibchen auf. Auf dem Foto ist ein Bitterlingsweibchen mit Legeröhre zu sehen (Foto: Andreas Hartl).
Rückbildung der Legeröhre in normalem Wasser. Die „Treffsicherheit" von $80 \%$ lag unter dem damals üblichen Mäusetest nach Aschheim (98\%). Die schnellere Ansprechzeit von 24-48 Stunden im Vergleich zum Mäusetest (Veränderungen in den Mäuseovarien ca. 100 Stunden nach Harninjektion) und das Überleben der Testtiere und damit deren Wiedereinsetzbarkeit waren Vorteile des Bitterlingstests. Er wurde vor allem Ende der 1920er- bis in die 1940er-Jahre propagiert (Originalliteraturzitate bei Friesen 1940). Heute durch die Bestimmung des humanen Choriongonadotropins ( $\triangleright$ Choriongonadotropin, humanes) im Schwangerenharn ersetzt.

\section{Literatur}

Friesen G (1940) Die Legeröhre des Bitterlings als Testobjekt bei der Schwangerschaftsdiagnose. Wschr. f. Aquarien- und Terrarienkunde $37: 525-526$

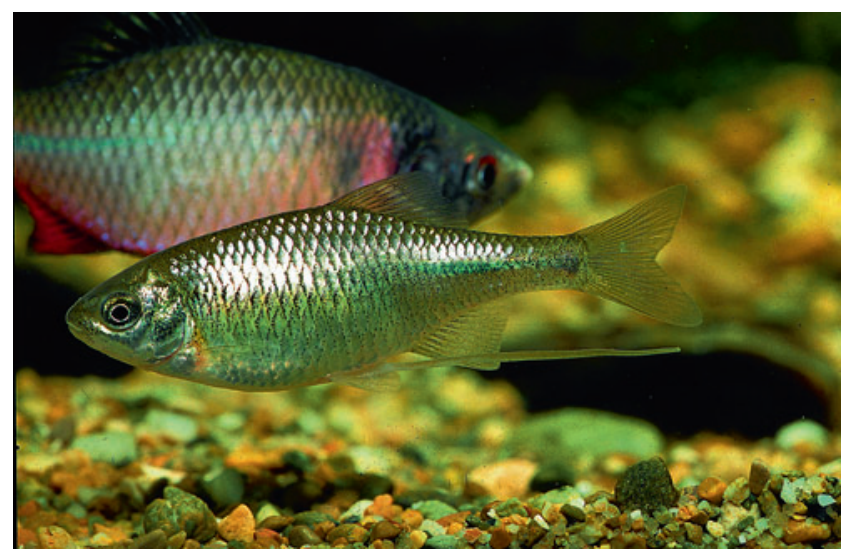

